\title{
Fiber Optic Oscilloscope Probe
}

\author{
B. Lee
}

This article was submitted to PPPS-Pulsed Power Plasma Science 2001, Las Vegas, NV ,, June
17-22, 2001

\section{June 11, 2001}

U.S. Department of Energy

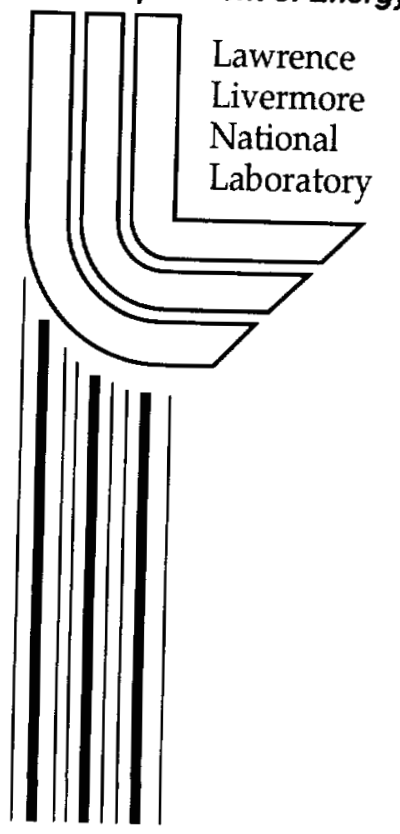




\section{DISCLAIMER}

This document was prepared as an account of work sponsored by an agency of the United States Government. Neither the United States Government nor the University of California nor any of their employees, makes any warranty, express or implied, or assumes any legal liability or responsibility for the accuracy, completeness, or usefulness of any information, apparatus, product, or process disclosed, or represents that its use would not infringe privately owned rights. Reference herein to any specific commercial product, process, or service by trade name, trademark, manufacturer, or otherwise, does not necessarily constitute or imply its endorsement, recommendation, or favoring by the United States Government or the University of California. The views and opinions of authors expressed herein do not necessarily state or reflect those of the United States Government or the University of California, and shall not be used for advertising or product endorsement purposes.

This is a preprint of a paper intended for publication in a journal or proceedings. Since changes may be made before publication, this preprint is made available with the understanding that it will not be cited or reproduced without the permission of the author.

This work was performed under the auspices of the United States Department of Energy by the University of California, Lawrence Livermore National Laboratory under contract No. W-7405-Eng-48.

This report has been reproduced directly from the best available copy.

Available electronically at http://www.doc.gov/bridge

Available for a processing fee to U.S. Department of Energy

And its contractors in paper from

U.S. Department of Energy

Office of Scientific and Technical Information

P.O. Box 62

Oak Ridge, TN 37831-0062

Telephone: (865) 576-8401

Facsimile: (865) 576-5728

E-mail: reports@adonis.osti.gov

Available for the sale to the public from

U.S. Department of Commerce

National Technical Information Service

5285 Port Royal Road

Springfield, VA 22161

Telephone: (800) 553-6847

Facsimile: (703) 605-6900

E-mail: orders@ntis.fedworld.gov

Online ordering: http://www.ntis.gov/ordering.htm

OR

Lawrence Livermore National Laboratory

Technical Information Department's Digital Library

http://www.llnl.gov/tid/Library.html 


\title{
FIBER OPTIC OSCILLOSCOPE PROBE*
}

\author{
Bryan Lee \\ Lawrence Livermore National Laboratory \\ 7000 East Avenue, Livermore, California, 94551 \\ L645
}

\section{Abstract}

In the recent development of high voltage solid state pulsed power systems, the ability to monitor low voltage signals in a high voltage environment has been a problem. The amplitude of any ground bounce from the high voltage pulse can make the interpretation of low voltage diagnostic signals difficult with industry standard probes.

The paper explains the development of a fiber optic voltage probe for the oscilloscope. Included are explanations of the probe's design, fabrication, limitations, and performance when compared with standard probes in a high voltage pulsed power environment.

\section{INTRODUCTION}

The Beam Research Program at Lawrence Livermore National Laboratories has been developing a Solid State Kicker Pulser for DARHT-2. The pulser is a $20 \mathrm{kV}$ induction adder circuit with rise and fall times of less than 10ns. The pulser is designed around an array of MOSFETs. A critical diagnostic point for monitoring and troubleshooting this pulser is the gate of the MOSFET. In this confined high voltage pulse environment, noise and ground bounce become an issue when attempting to monitor low level gate pulses $(5 \mathrm{v}-$ i $5 v$ ). A method of monitoring the gate pulse while the high voltage pulse is being switched was needed. The development of a fiber optic oscilloscope probe was necessary to provide a way to conveniently monitor any gate pulse without hardwiring an optical transmitter into the circuit.

\section{DESIGN}

This probe was designed specifically for looking at the voltage waveform of the gate of a MOSFET. With the complete understanding of its design and limitations, it could be used for other purposes. (Figure 1).

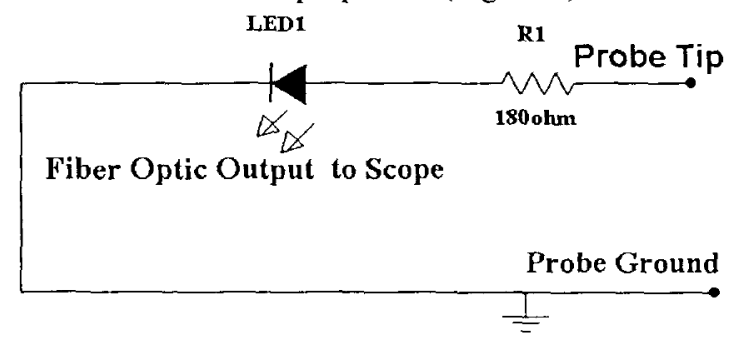

Figure 1. Circuit
The biggest factor in the performance of this probe is the value chosen for the series resistor (Figure 1. R1). With the circuit inductance dictated by the physical design of the probe, the resistance must remain large enough to achieve the rise and fall times desired. Keeping the resistance high enough to achieve these fast rise and fall times also limits the total current through the fiber optic transmitter. Limitations caused by this current level will be addressed later. This probe was designed to measure a specific pulse $(15 \mathrm{~V}, 20 \mathrm{~A})$ and to have a fast rise and fall time. By varying the value of $R 1$ the probe can be customized for specific applications.

\section{FABRICATION}

The optical probe was fabricated from a damaged Tektronix P6139A probe and modified to accept a fiber optic transmitter and a current limiting resistor (Figure 26). While many probes or transmitters may be used, the transmitter chosen for this probe was a PD-LD SLED. Part \#. PLD-S08-191-080-PH2. By terminating the end of the fiber onto an ST connector, it can be inserted into an optic/electrical converter and then to an oscilloscope. These optic/electrical converters are available throughout the industry for minimal cost. Fir probe, a series resistor of $180 \Omega$ was chosen.

A. Low Inductance Fabrication Procedure

1) Start with parts from a Tek. P6139A probe. Figure 2

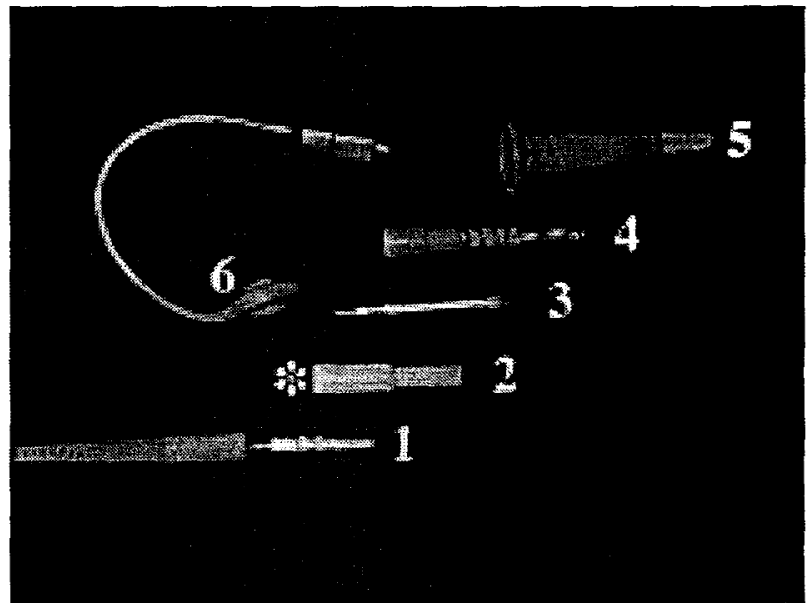

Figure 2. Parts from a Tek. P6139A probe. Refer to numbered parts for assembly procedure.

2) Drill out half of part \#2 (*) to 13/64"

3) File the outside of part \#2 $(*)$ to fit into part \#4

*This work performed under the auspices of the U.S. Department of Energy by the University of California, Lawrence Livermore National Laboratory under Contract No. W-7405-Eng-48 
4) Drill out part \#3 to 7/64" leaving only the metal.

5) Drill a small hole in part \#4. (Figure 3)

6) Remove plastic from part \#4 to expose the probe tip. Your resistor must fit between the drilled hole and newly exposed probe tip. (Figure 4)

7) Run Fiber through parts 3, 2(* end first), 6, 1, and the strain relief in that order.

8) Remove case lead and small strain relief from transmitter.

9) Insulate anode lead of transmitter and fold back cathode lead to touch the case.

10) Connect part \#3 and cathode to transmitter body with silver cpoxy. (Figure 5)

11) Slide part\#2 over transmitter and feed the transmitter and part \#2 into part \#4 so that the anode protrudes through the hole and makes contact with the series resistor. (Figure 6)

12) Use silver epoxy to make contact from anode to resistor and resistor 10 probe lead. The epoxy can also be used to secure part \#2 to part \#4. Make sure 10 maintain contact between part \#3 and the transmitter body while assembling

13) After epoxy dries thread part \#3 and Part \#1 together, insert part \#4 into part \#5, attach strain relief.

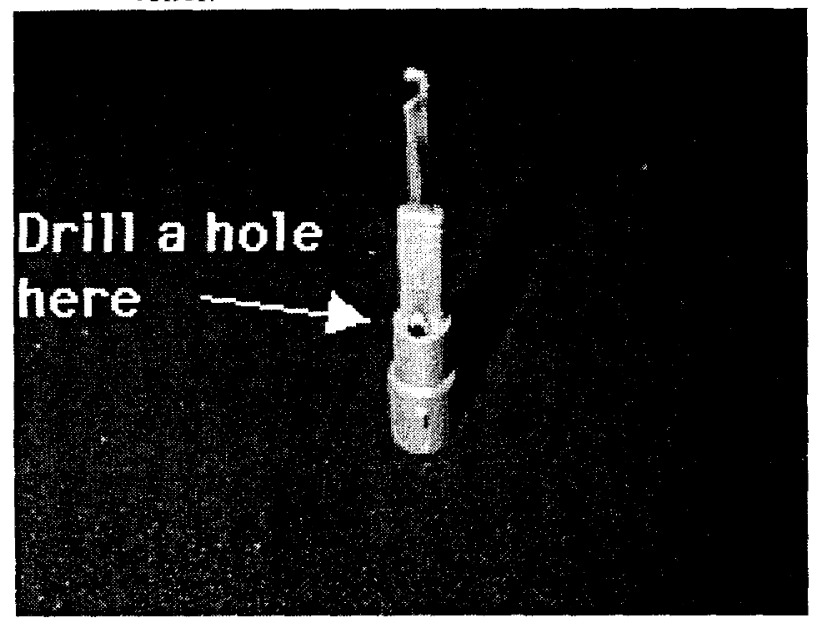

Figure 3. Create a hole for the transmitter anode.

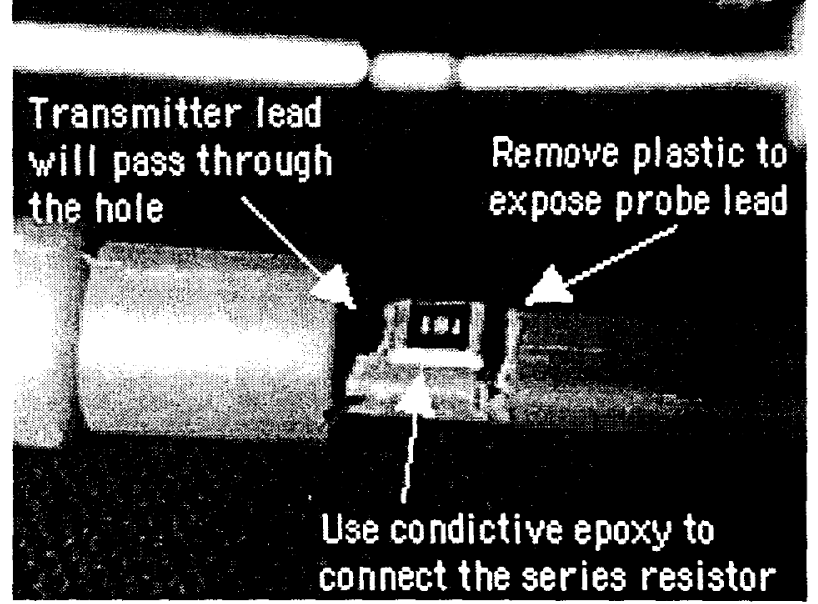

Figure 4. Remove the plastic to expose the probe tip conductor. Silver (conductive) epoxy will be used later.

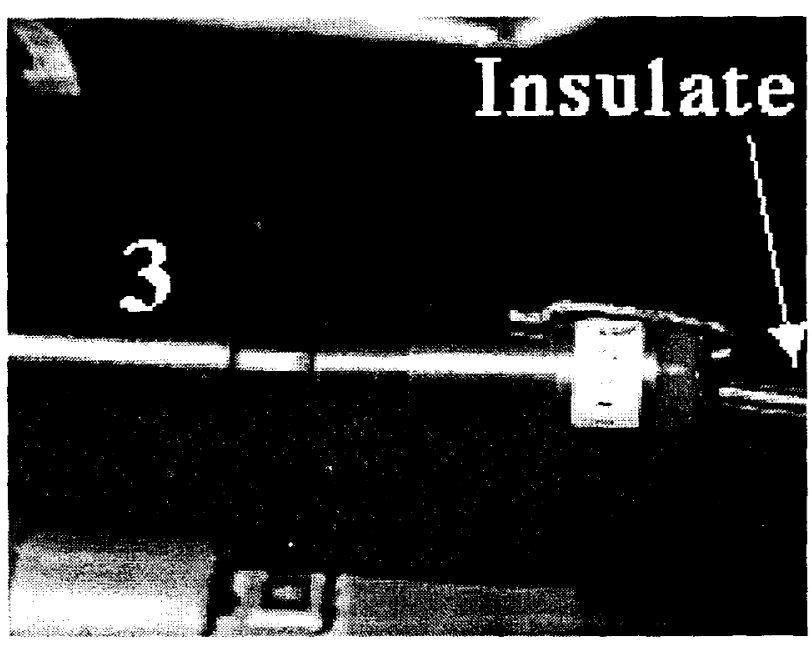

Figure 5. Connect part \#3 and the transmitter body with silver epoxy.

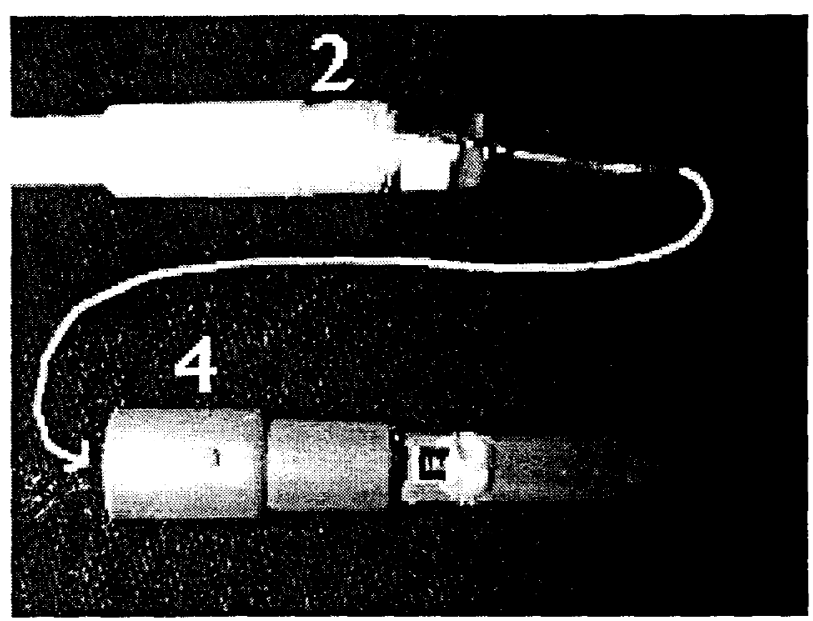

Figure 6. Allow the transmitter and resistor connections to dry before installing part \#2 into part \#4.

The key in the fabrication is to keep the inductance as low as possible. By modifying an old probe you can take advantage of low inductance hardware, use the flexibility already designed into the old probe, and save the cost of custom machining.

\section{LIMITATIONS}

This probe has the following limitations and for these reasons may not be suitable for use in all applications.

\section{A. Pulse Width}

The Fiber Optic Transmitter (Figure I. LEDl) requires a forward bias to turn it on. This will cause a propagation delay for the rise time. Likewise, during the fall time once the signal falls below this threshold the signal will turn off. The total pulse width measured by this prote will he less then the actual pulse width being measured 


\section{B. Amplitude}

The amplitude of the measured pulse is a measurement of optical power $(\mu \mathrm{W})$. This optical power is the result of many factors. Bends in the optical fiber, coupling at connections, and most important the amount of current flowing through the transmitter. Variations in these factors make the probe difficult to calibrate to a specific $\mu w / v o l t$, but still allow for an accurate measurement of the waveshape.

\section{Current Draw}

This probe is not a high impedance probe. Current must pass through the transmitter in order for it to work. This probe will draw current from and affect the circuit being monitored.

\section{Nonlinearity}

The transmitter selected for this probe maintains linearity at higher currents but lacks it at lower levels (Figure 7.)

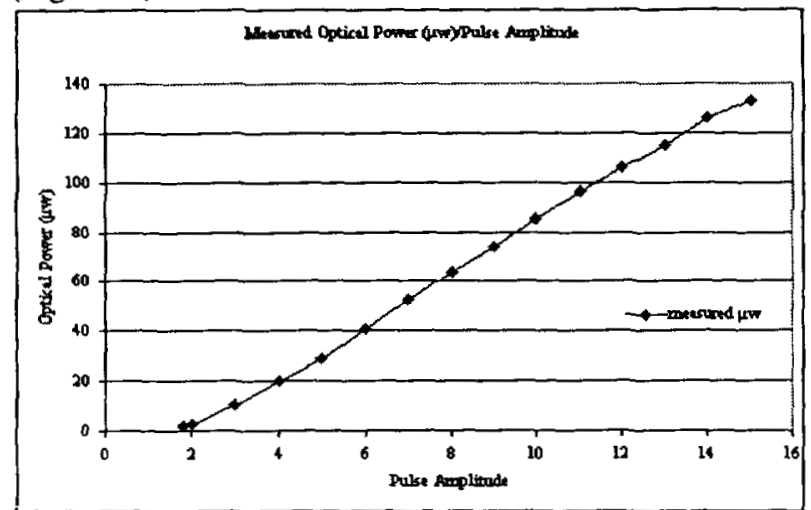

Figure 7. Notice knee at lower amplitudes

\section{E. Sensitivity to DC Measurement}

This probe works by drawing current from the circuit being tested. On a DC rail the probe will provide a path for continuous current to ground. This will work as a probe but precautions need to be taken to insure that the maximum power ratings for both the transmitter and the series resistor are not exceeded. The forward bias voltage of the transmitter should also be taken into account when attempting to measure a DC rail.

\section{F. No Negative Measurement Capabilities}

The transmitter is a diode and only allows current to pass in the forward direction. Figure 11.

\section{PERFORMANCE}

This probe, in some applications, has limitations when compared with probes currently available in the industry. However, for the application it was designed it performs very well. This probe is designed to observe a $15 \mathrm{~V}, 20 \mathrm{~A}$, gate pulse on a MOSFET switching $600-700$ volts. The test circuit for Figures 8-10 consists of a pulse generator or arbitrary waveform generator connected directly to an oscilloscope. The signal is directly coupled by coaxial

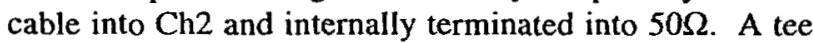
is installed at the oscilloscope and serves as a monitor point for the optical probe.

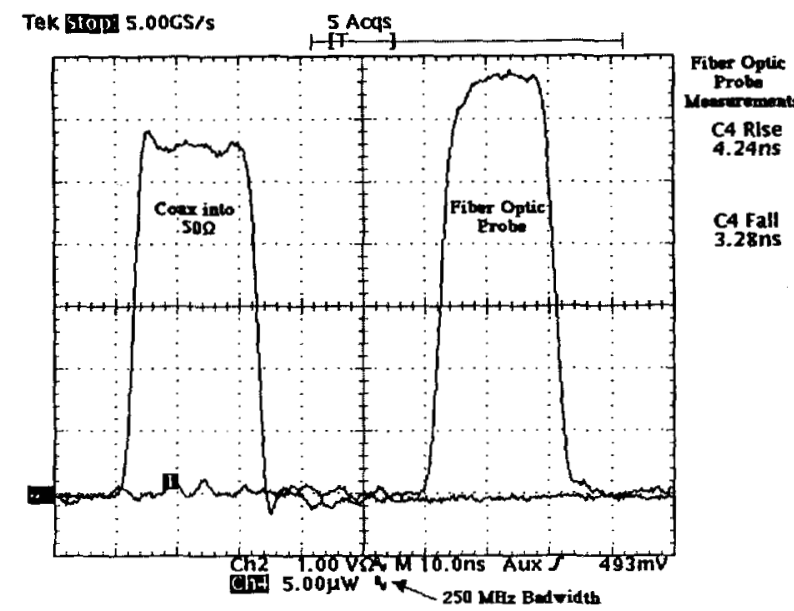

Figure 8. $6 \mathrm{~V}$ 20ns pulse. $10 \mathrm{~ns} / \mathrm{div}$

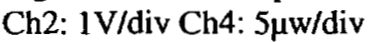

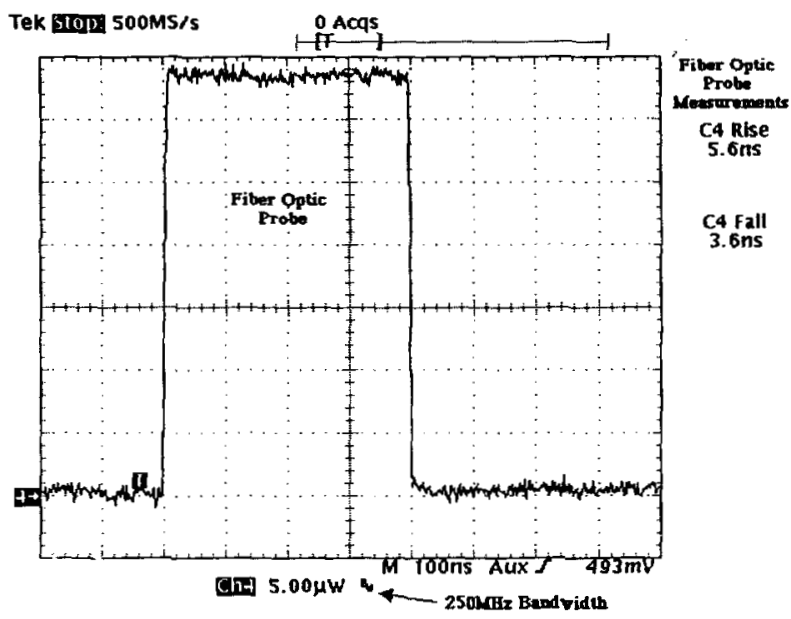

Figure 9. $6 \mathrm{~V}, 400 \mathrm{~ns}$ pulse. $100 \mathrm{~ns} / \mathrm{div}$

Ch4: 5uw/div

The Fiber Optic probe measures long pulses without problems (Figure 9). The best way to use this probe is to calibrate it against a known waveform before the high voltage switching is performed. By adjusting the scale $(\mu \mathrm{W} / \mathrm{div})$ to match the waveform of a standard probe the Fiber Optic probe can provide data which translates to a volts/div (Figure 10).

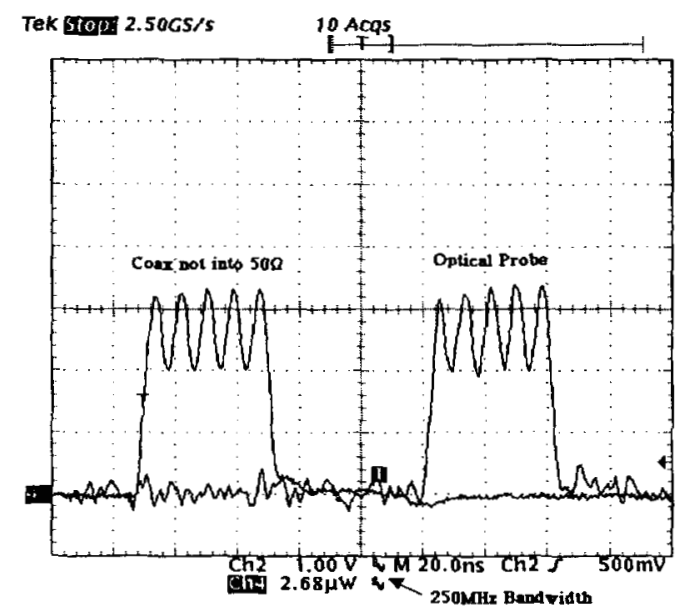

Figure 10. 20ns/div. 
Figure 11 is a measurement of the waveform this probe was designed to monitor. No voltage is being switched through the MOSFET. This picture also demonstrates the probe's inability to monitor negative voltage. Figure 12 shows both the Fiber Optic probe and the Tek. P6139A probe measuring a single gate pulse while the MOSFET is switching $625 \mathrm{~V}$. In this high voltage environment you can see the benefits of the Fiber Optic probe over other probes. The Tek. P6139A is picking up induced noise from the High Voltage Pulser.

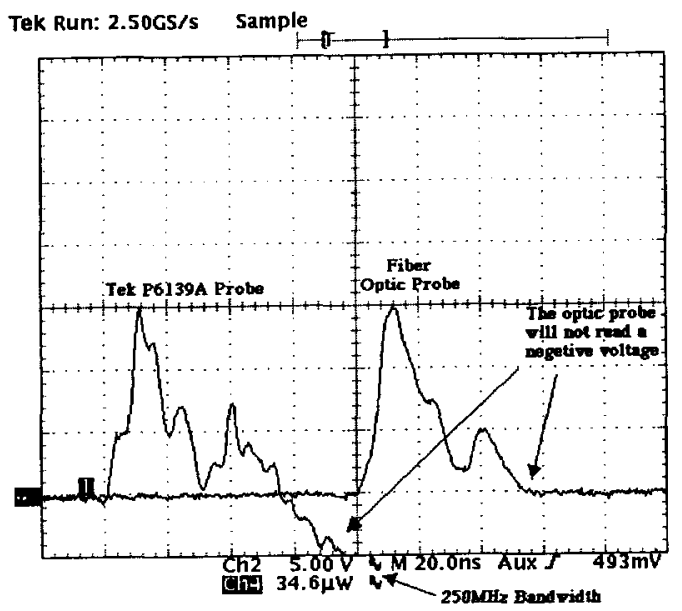

Figure 11. $15 \mathrm{~V}, 30 \mathrm{~ns}$, Gate pulse. $20 \mathrm{~ns} / \mathrm{div}$. Ch2: Tek. P6139A probe, $5 \mathrm{~V} /$ div.

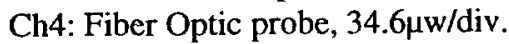

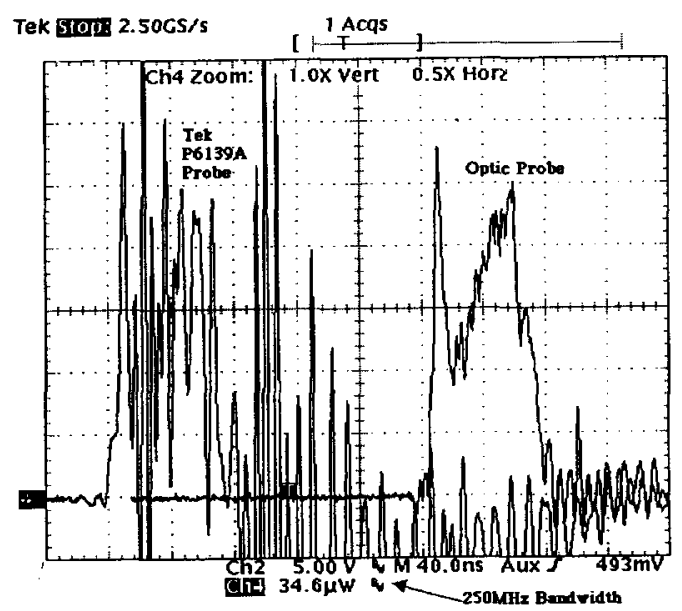

Figure 12. $15 \mathrm{~V}, 70 \mathrm{~ns}$, Gate pulse. $40 \mathrm{~ns} / \mathrm{div}$.

Ch2: Tek. P6139A probe, 5V/div.

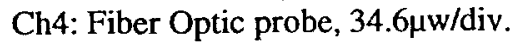

By monitoring this gate pulse with the Fiber Optic probe it is much easier to determine how long and when the MOSFET was commanded to switch.

\section{SUMMARY}

A fiber optic probe can be fabricated to monitor low voltage signals in a high voltage environment. With proper component selection a fiber optic probe will produce useful measurements not easily obtainable by other probes. Consideration should be given to the waveforms to be monitored while in the early stages of the probes design.

\section{REFERENCES}

R. Saethre, H. Kirbie, B. Hickman, B. Lee, C. Ollis, "Optical control, diagnostic and power supply system for a solid state induction modulator", in Proc. $11^{\text {th }}$ IEEE Int. Pulsed Power Conference, 1997, pp.1264-1269 Vol. 2. 